\title{
E-mail communication in the management of gastroenterology patients: A review
}

\author{
Ian Plener $\mathrm{MD}^{1}$, Andrew Hayward $\mathrm{MD}^{1}$, Fred Saibil MD ${ }^{1,2}$
}

\begin{abstract}
I Plener, A Hayward, F Saibil. E-mail communication in the management of gastroenterology patients: A review. Can J Gastroenterol Hepatol 2014;28(3):161-165.
\end{abstract}

E-mail correspondence between physicians and patients can be a useful tool to improve communication efficiency, provide economic and ecological benefits, improve therapeutic interventions and adherence, and enhance self-management. The model of self-management in chronic disease has become an integral component of North American and British medicine. From a practical standpoint, the use of e-mail between physicians and patients can complement the self-management model.

E-mail communication has many benefits from both patient and physician perspectives. E-mail contact reduces the inefficiencies associated with telecommunications. Physicians are able to better document out-of-office patient encounters and provide access to specialist care for patients in remote locations. This use of e-mail has the potential to increase patient safety through physician approval of self-manager actions, including earlier initiation of needed treatments. Fewer clinic visits afford additional time for new consultations and sicker patients, reducing the overall burden on referral and wait times.

The present article reviews some of the literature regarding physicianpatient e-mail communication in the general ambulatory setting, in the context of chronic disease and with a specific focus on inflammatory bowel disease (IBD). The authors provide a framework for the use of e-mail communication in the IBD population, with emphasis on the concept of e-mail use. Also illustrated are the benefits and disadvantages, and examples of the e-mail contract as proposed by the Canadian Medical Protective Association. Examples of specific e-mail communication topics are provided for several IBD scenarios. Potential negative consequences of this mode of communication are also discussed.

Key Words: Electronic mail; E-mail; Inflammatory bowel disease; Patientphysician communication; Self-management

- - -mail correspondence is a universal mode of communication; howEever, its implementation in medical practice is not widespread. According to Statistics Canada data from 2010, 80\% of individuals $>16$ years of age used the Internet for personal use, from home, work or elsewhere (1). Of those, $64 \%$ conducted online searches for medical or health-related information (1). Increasingly, patients now use the Internet to access health web sites and physician web pages $(2,3)$. Internet statistics in the United States indicate that e-mail has become the main form of communication for $>90 \%$ of users (4). According to a Harris Online poll conducted in 2005, 70\% of online adults in the United States wanted to be able to e-mail their doctors and, of those, $37 \%$ were willing to pay out-of-pocket to compensate physicians for this service $(5,6)$. Additionally, there has been a significant increase in patient demand for e-mail contact with their physicians $(7,8)$. E-mail has been evaluated as an avenue for communication between physicians and patients/caregivers for its potential benefits in improving service efficiency, cost savings, improvements to patient

\section{Les communications par courriel dans la prise en charge des patients en gastroentérologie}

Les correspondances par courriel entre médecins et patients peuvent être utiles pour améliorer l'efficacité des communications, présenter des avantages d'ordre économique et écologique, accroître les interventions et l'observance thérapeutiques et améliorer l'autogestion. Le modèle d'autogestion des maladies chroniques fait désormais partie intégrante de la médecine nord-américaine et britannique. Sur le plan pratique, les courriels entre médecins et patients peuvent compléter ce modèle.

Les communications par courriel comportent de nombreux avantages pour les patients et les médecins. Ainsi, elles réduisent les inefficacités associées aux télécommunications. Les médecins sont mieux en mesure de répertorier les conseils aux patients hors du cabinet et d'offrir des soins spécialisés aux patients des régions éloignées. Cette utilisation des courriels peut accroître la sécurité des patients, car les médecins peuvent approuver leurs mesures d'autogestion, y compris l'amorce plus rapide de traitements nécessaires. La diminution du nombre de rendez-vous en cliniques dégage du temps pour les nouvelles consultations et les patients plus malades et réduit le fardeau global des aiguillages et des temps d'attente.

Le présent article présente une analyse bibliographique partielle des communications par courriel entre médecins et patients en milieu ambulatoire en cas de maladies chroniques, notamment les maladies inflammatoires de l'intestin (MII). Les auteurs présentent un cadre d'utilisation des communications par courriel au sein de la population atteinte de MII et s'attardent sur le concept d'utilisation des courriels. Ils en exposent également les avantages et les inconvénients et donnent des exemples du contrat d'utilisation des courriels proposé par l'Association canadienne de protection médicale. Ils proposent aussi des exemples de sujets de communications par courriel dans quelques scénarios liés aux MII. Ils abordent enfin le potentiel de conséquences négatives de ce mode de communication.

${ }^{1}$ Department of Medicine, University of Toronto; ${ }^{2}$ Division of Gastroenterology, Sunnybrook Health Sciences Centre, Toronto, Ontario

Correspondence and reprints: Dr Fred Saibil, Sunnybrook Health Sciences Centre, 2075 Bayview Avenue, Room H-52, Toronto, Ontario M4N 3M5.

Telephone 416-480-4727, fax 416-480-5977, e-mail fred.saibi@utoronto.ca

Received for publication November 24, 2013. Accepted November 29, 2013

outcomes, ecological benefits and enhancement of self-management programs in chronic disease. As far back as 1994, the majority of patients from two studies in family practice and internal medicine regarded e-mail communication as a means to improved efficiency, access to medical care, and convenient for employees and students (9). Couchman et al (9) reported that $90 \%$ of surveyed patients in the ambulatory setting were interested in using e-mail for prescription refills, $78 \%$ in scheduling appointments, $87 \%$ in booking nonurgent consultations and $84 \%$ in obtaining diagnostic test results. However, the health care industry has been cautious in accepting this medium. In 1998, only 7\% of American physicians e-mailed their patients (10). In a review of health care provided to university students in Finland, the volume of e-mail correspondence averaged $7.7 \mathrm{e}$-mails per patient per month $(3,11)$. In this population, similar to many primary care scenarios, e-mail communication was used for nonurgent matters. More recently, however, American studies demonstrate that e-mail communication use among physicians has increased to $16 \%$ in primary 


\begin{tabular}{|c|}
\hline $\begin{array}{l}\text { BOX 1: E-mail management } \\
\text { Advantages to e-mail management }\end{array}$ \\
\hline $\begin{array}{l}\text { Enhanced convenience of communication outside of traditional office } \\
\text { hours }(30) \text {. }\end{array}$ \\
\hline $\begin{array}{l}\text { Improved documentation, correspondence audits and confirmation with } \\
\text { read receipts. }\end{array}$ \\
\hline $\begin{array}{l}\text { Valuable written reference for the patient, improving information recall and } \\
\text { providing evidence of the communication }(6,32) \text {. }\end{array}$ \\
\hline Improves physician accessibility for nonurgent communications (14). \\
\hline Reliable communication modality for patients with disabilities. \\
\hline $\begin{array}{l}\text { Effective communication with patients who are temporarily traveling abroad, } \\
\text { away for study or in remote communities. }\end{array}$ \\
\hline Efficient and potentially minimizes cost of information delivery to patients (26). \\
\hline $\begin{array}{l}\text { Adjunct to self-management paradigm to free up clinic resources for sicker } \\
\text { patients. }\end{array}$ \\
\hline Disadvantages to e-mail management \\
\hline $\begin{array}{l}\text { Patient and physician concerns about privacy, confidentiality and potential } \\
\text { misuse of information (7). }\end{array}$ \\
\hline $\begin{array}{l}\text { Physicians' concern regarding possibly increased, nonremunerated } \\
\text { workload (32). }\end{array}$ \\
\hline Patients' expectations regarding timely replies may be problematic $(9,12)$. \\
\hline Impersonal nature of email communication (16). \\
\hline Potential misuse of email for urgent clinical matters (9). \\
\hline Economics of implementing secure, encrypted web-based servers. \\
\hline Medico-legal issues, including informed consent (33). \\
\hline Technological glitches (eg, redirect back to sender, unintended recipients) (31). \\
\hline Successful Implementation \\
\hline Integrate a secure, encrypted, confidential web messaging system. \\
\hline $\begin{array}{l}\text { Discussions with patients regarding appropriate use of e-mail and legal } \\
\text { implications (obtain informed consent). }\end{array}$ \\
\hline Standardized e-mail contract in accordance with CMPA (25). \\
\hline $\begin{array}{l}\text { Select patients suitable for email communication and establish } \\
\text { expectations (34). }\end{array}$ \\
\hline $\begin{array}{l}\text { Monitor level of usage - prescription renewals, appointment bookings, } \\
\text { management dialogue }\end{array}$ \\
\hline Establish mechanism for tracking and following up on e-mail misuse. \\
\hline *Numbers in parentheses refer to references \\
\hline
\end{tabular}

care, and as much as $72 \%$ in large outpatient settings (5). As with any form of new communication, transformation takes time. While telephone contact was initially met with some resistance, physicians now regularly use telephones, pagers and faxes.

\section{E-MAIL USE IN PRIMARY CARE}

E-mail communication between patients and health care professionals can take several forms as an adjunct to in-person consultation. Primary care physicians and their patients have demonstrated a preference for e-mail over telephone consultations for nonurgent matters such as uncomplicated urinary tract infections, chronic back pain, sore throats, hypercholesterolemia and Pap smear results (12-16). Patients and physicians managing primary care issues have endorsed e-mail use for many years (16). E-mail has also been used to optimize adherence and compliance to treatment, through communicating reminders to patients, as well as inquiries regarding medication side effects and treatment duration (17). Furthermore, e-mail use in the form of patient follow-ups (eg, after an initial appointment), when clarification or additional information may be required or before an office visit for medical updates may be beneficial $(14,15,18)$. Physician-patient e-mail may also be used to notify patients of instructions in preparation for tests or to acquire screening information using a questionnaire.

\section{E-MAIL USE IN CHRONIC DISEASE MANAGEMENT}

E-mail can play a valuable role in enhancing the management of chronic diseases by improving continuity of care while allowing health care professionals flexibility in responding to nonurgent issues, with the side benefit of affording consultation time for sicker patients

\section{BOX 2: Sample e-mail dialogues for inflammatory bowel} disease patients

Patient: colitis flaring; doubled my 5-ASA.

Gastroenterologist: good; report in 5-7 days; if no recent antibiotics/ travel, and not getting better, start pred $40 \mathrm{mg}$ daily - if you go on pred, tell us and my secretary will give you an apptmt (CC email to secretary)

Patient: think l've got another blockage, bloated, cramps, no BMs

Gastroenterologist: clear fluids only $\times 36 \mathrm{~h}$, then try to progress diet; report in $48 \mathrm{~h}$ to $72 \mathrm{~h}$

Patient: on azathioprine; had blood test yesterday

Gastroenterologist: test fine; repeat $3 \mathrm{mths}$

Patient: do you have my colonoscopy results?

Gastroenterologist: all biopsies fine; repeat in $2 \mathrm{yrs}$, but see you in $1 \mathrm{yr}$

ASA Aminosalicylic acid; BMs Bowel movements; mths Months; yr Year(s)

$(12,18)$. The model of self-management in chronic disease has become an integral component of North American and British medicine (7). Successful self-managers are now commonplace in the setting of reactive airway disease, type II diabetes mellitus, congestive heart failure, recurrent urinary tract infections, chronic obstructive pulmonary disease and long-term anticoagulation (19,20). Patients with inflammatory bowel disease (IBD) have also been successfully managed using this paradigm (21). E-mail correspondence between physicians and patients improves communication efficiency, leads to more rapid therapeutic interventions, improves compliance and adherence to therapeutic regimens, provides economic and ecological benefits, and enhances the self-management model.

Innovative physician-patient communication methods, such as e-mail, can help confront the issue of increasing wait times, provide patients in remote communities with easy access to specialist care and reduce office inefficiencies. We believe that the use of e-mail between physicians and patients provides a useful adjunct to the self-management model in chronic disease (Box 1).

\section{E-MAIL USE IN GASTROENTEROLOGY}

Little has been published related to the use of e-mail in the field of gastroenterology. With respect to patients with irritable bowel syndrome, patients' expectations regarding the quality and quantity of communication with their physician is paramount (5). E-mail communication may serve as a useful adjunct to provide patients with additional educational content, detailed explanations of their condition, serve to answer follow-up questions and enhance appointment scheduling (5). In an overwhelming majority of patients, the above are essential qualities that contribute to overall patient experience and their opinion of their gastroenterologist (5). To our knowledge, e-mail communication has not been studied in other areas of gastroenterology.

\section{E-MAIL USE IN IBD}

There is a paucity of literature regarding e-mail communication in the management of IBD. Specifically related to IBD, Cross and Finklestein (22) advanced the self-management paradigm with a study focusing on the feasibility of home telemanagement for patients. Telemanagement may be helpful in selected patients; however, e-mail requires only a computer and Internet access. For the past seven years, the senior author of the present article (FS) has been using e-mail to support selfmanagers. The integration of e-mail into the self-management paradigm has clear benefits in Canadian health care and should be applicable to all health care models (21) (Box 2).

IBD self-managers may also benefit from reassurance, via e-mail, when experiencing minor flares. A randomized controlled trial conducted by Kennedy et al (23) assessed quality of life, health service resource use and patient satisfaction in 700 patients after 12 months of implementing a self-management approach. Self-managers had fewer hospital visits without increases in primary care visits, an improvement in quality of life and reduction in anxiety (23). Based on a 
BOX 3: Sample e-mail history form, with replies for new patient in italics

Have you ever been hospitalized overnight for anything? Any operations? Why? Yes, in 1978 for bladder reflux surgery.

Describe your problem - if you are having any gastro-intestinal symptoms, or say "none". Cramping in lower abdomen, alternating between diarrhea and constipation, red blood in stool, gassy and bloated abdomen. Sore to touch and fatigue.

Do you smoke? How much and for how many years? Quit? For how many per year? Yes, quit approximately 2 months ago. Smoked since a teenager.

Do you drink alcohol? How many beers/glasses of wine/drinks of liquor a day or a week or a month? Please reply for each type of beverage. I do not consume alcohol. Never have.

How's your appetite? Have you lost any weight recently? How much? On purpose? Still losing? Appetite varies. Hunger to nausea. No significant weight loss or gain.

Any trouble swallowing? Nausea? Vomiting? Heartburn or indigestion? If yes to any of these, how long is problem present, and how many times a day or a week or a month does it occur? N/A

Any pains in your abdomen? Please describe - where in your abdomen, constant or intermittent, duration of each episode if intermittent, severity, anything that makes it worse, anything that makes it better? Yes, pain in lower abdomen. Radiates from centre to both sides. Somewhat constant over last two weeks.

How often do you have a bowel movement (BM)? Daily? Every 2nd day? Solid or loose? Any bleeding? Do you get up from sleep to have bowel movements? Any urgency? If urgent, mild, moderate, or severe? Bowel movement can range from daily to every few days. Intermittent blood in stool. Always suffered from irregularity. Do not get up during sleep.

List $\underline{A L L}$ medications, doses and reasons for being on them, whether prescribed or not. Not currently on any medications.

Are you allergic to any drugs? If yes, describe reaction. No

Please tell me about your family history; anyone with colon cancer or colon polyps; any other kind of cancer in the family; any diseases that "run" in the family? Diabetes on mother's side, paternal grandfather died of stomach cancer, mother has polyps.

Do you have heart disease? Lung disease? Kidney disease? High blood pressure? Any other disease? No diseases.

Do you have sleep apnea? No

What do you do for a living? Mental Health Community Crisis Worker.

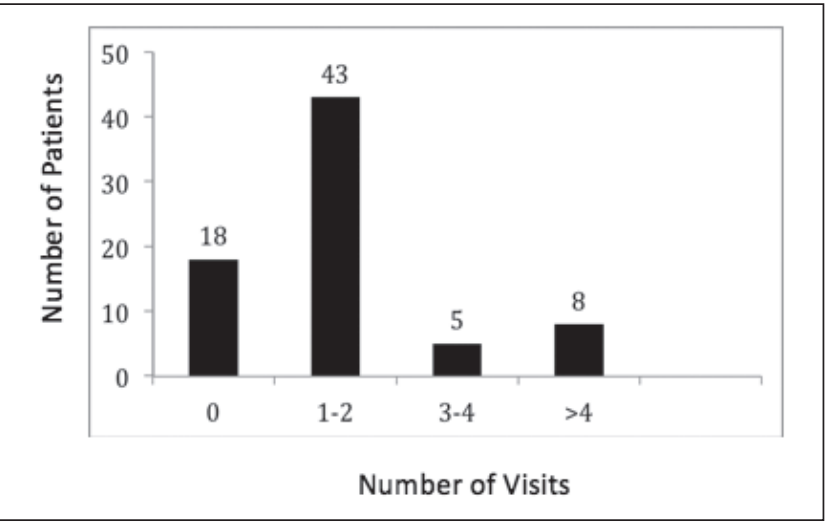

Figure 1) Number of clinic visits by patients over a six-month period

patient's report of a disclosed symptom set, the experienced physician can assess whether a patient needs to be seen in the same way that is currently achieved with telephone calls (21). In the senior author's (FS) practice, e-mail is being used frequently, especially for IBD patients living and working at a distance from the clinic. Although many of these communications pertain to blood test results, other common uses include advice regarding steroid dosing and fine-tuning of management regimens. Patients undergoing pharmacotherapy, such as immunosuppressants, frequently require regular blood work monitoring and assessment of adverse effects. Patients can easily inform physicians when they have gone for a blood test and then can receive a response indicating normal or abnormal values. Abnormal values would prompt some form of follow-up (which may be in the form of additional e-mail), whereas normal values would merely be noted by an e-mail indicating the time for the next routine test. By adding e-mail as a means of triaging self-managers, additional clinic time with shorter wait times can be made available for new consultations and sicker patients requiring in-person assessment.

\section{AUTHORS' EXPERIENCE}

In a pilot study conducted by the senior author and clinical trainees at Sunnybrook Health Sciences Centre (Toronto, Ontario) evaluating e-mail management in patients with IBD, e-mail communication appeared to have many benefits from both patient and physician perspectives (24). A patient questionnaire was administered via e-mail to 137 consenting IBD patients with a minimum six months of e-mail communication. Seventy-four (54\%) patients responded to the survey.

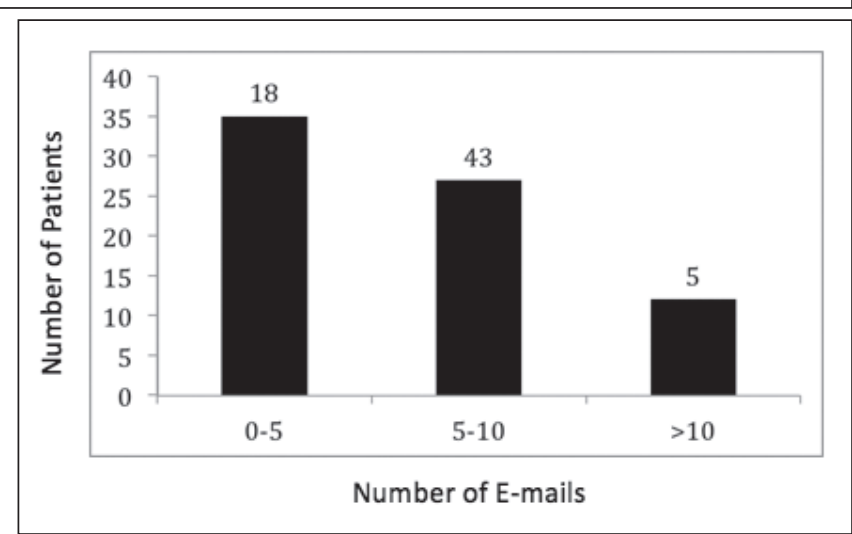

Figure 2) Number of e-mail exchanges between patients and their specialist over a six-month period

The five main question categories included: e-mail usage, economic impact, number of clinic visits, convenience and demographics. Main outcomes measured included: e-mails sent, hours lost from work, distance travelled, specialist clinic visits, hours taken per appointment, anxiety scale and patient preference (Box 3).

Reviewing six months of e-mail communication, $76 \%$ of e-mailmanaged IBD patients estimated that they made at least one to two fewer visits to the clinic (Figure 1). To attend the clinic, $65 \%$ of participants commuted $>3.1$ miles $(5 \mathrm{~km})$ to 6.2 miles $(10 \mathrm{~km})$ from home, and $73 \%>3.1$ miles $(5 \mathrm{~km})$ to 6.2 miles $(10 \mathrm{~km})$ from their place of employment. More than 50\% travelled for longer than $30 \mathrm{~min}$. Fifty-three percent of participating patients exchanged e-mail with their specialist on more than five to 10 occasions during the six-month period (Figure 2). Additionally, 77\% of patients reported a reduction in their stress level regarding their IBD management. When given a choice between traditional health care delivery (clinic visits only) and clinic visits combined with e-mail access, $90 \%$ of patients preferred the combined model. Further evaluation with a rigorous protocol is planned to better evaluate the short-term and long-term benefits of e-mail management in patients with IBD.

\section{QUALITY, SAFETY AND LEGAL IMPLICATIONS}

It is clear that e-mail consultations are not always suitable. Individuals with urgent questions and/or issues must be made aware that they should either telephone the doctor's office or go to an emergency department, particularly with symptoms such as neurological deficits, dyspnea, chest pain or severe pain in any other location (16). 
Similarly, for intimate issues, such as mental health or substance abuse, a more direct interaction is generally preferable $(14,17)$. In some circumstances, patients may require a follow-up by the physician through a telephone call or in-person consultation due to incomplete or vague details via e-mail (18). The potential for e-mail use will vary from patient to patient (13). In addition, if either a physician or patient would prefer to discuss an issue in the office setting, an in-person consultation should be arranged.

Many physicians have expressed concerns regarding the use of e-mail communication, with emphasis on potential legal and security implications. However, it should be noted that the danger of personal information being directed to unintended recipients is equally as plausible as most current methods of communication including fax machines, voice mail and regular mail. As with any proposed intervention, it is the primary responsibility of the physician to discuss the legal risks, ensure confidentiality, maintain optimal standards of practice and require informed consent. It is also advisable to conduct e-mail communication using high-security servers and single-user computers to avoid potential breaches in security. With many of these legal implications in mind, the Canadian Medical Protective Association developed a formal arrangement between physician and patient by means of an e-mail contract in 2005 with a revised version in June 2013 (25). This contract outlines the risks associated with this type of interaction and clarifies the appropriate situations when e-mail is an acceptable choice. The senior author of the present article (FS) uses a personalized version of this contract.

The main quality and safety issues surrounding e-mail consultation include: patient confidentiality; identifying appropriate clinical situations for e-mail use; transcription errors and liability; e-mail integration into clinical models; and practice economics $(3,7,8,26)$. Secure, encrypted, web-based electronic messaging systems can address issues regarding security and liability that are associated with conventional e-mail communication (12). However, not all institutions have the available infrastructure and instead rely on standard e-mail communication (26). The responsibility for minimizing legal risks would fall on physicians who would be expected to adhere to the same rigid data protection rules expected of business and industry settings. E-mail encryption and safe data storage would also be required in addition to informed consent by the patient (26). It is important to select patients capable of using e-mail communication effectively (27). A subgroup of patients may be excluded from e-mail use for reasons including those with questionable reliability, the inability to understand appropriate use of e-mail and the technologically unskilled, among others. However, increased patient satisfaction has been noted in several studies of e-mail consultation, with patients preferring this method as a more convenient communication modality. In 2002, a United Kingdom-based survey by Potts and Wyatt (28) demonstrated that newly certified physicians have greater familiarity and comfort in using the Internet. This is not surprising given the expansion of technology into modern clinical practice and training. This illustrates a potential generational effect on Internet and e-mail consultation use.

\section{FINANCIAL AND WORKLOAD IMPLICATIONS}

When considering the use of e-mail in clinical practice, one needs to consider the time investment physicians require communicating with their patients. While time must be found for e-mailing, time will be freed up as a result of fewer telephone calls. Telephone calls require that both physician and patient be available at the same time within relatively few hours. On the other hand, e-mail enables patients to send messages at a time of convenience for them, and allows physicians to reply in the same fashion. In the senior authors' (FS) practice, patients are informed that e-mail is primarily for brief, nonurgent exchanges and that the physician may not reply for $24 \mathrm{~h}$ to $48 \mathrm{~h}$. In addition, as stated above, if the physician or patient would prefer to discuss an issue in the office setting, that request should be granted.

In the United States, e-mail management has been a billable activity for several years. While no Canadian fee schedule compensates physicians for e-mail at this time, the Ontario government, in conjunction with the Ontario Medical Association, has recently agreed to incorporate 'e-consultations' into health care delivery (29). Given the obvious benefits, it is anticipated that a fee structure will be developed.

\section{CONCLUSIONS}

From a practical standpoint, e-mail communication reduces the inefficiencies present with telecommunications. Physicians are able to document out-of-office patient encounters, reach patients efficiently and provide access to specialist care for patients in remote locations. This type of access has the potential to increase patient safety through physician approval of self-manager actions and earlier initiation of needed treatments. Fewer clinic visits affords additional time for new consultations and sicker patients, reducing the overall burden on referral and wait times. From the patient perspective, e-mail communication has reduced the need for primary care, and specialist and emergency visits. This has direct impact in reducing time required off work, with elimination of travel and significant reduction of the ecological footprint from fuel emissions.

While e-mail communication has clear benefits, the legal implications must be considered. Canadian Medical Protective Association e-mail contract provides an effective way of documenting informed consent and outlining the situations for which e-mail is appropriate. Akin to the voice mail of a physician's office instructing patients how to proceed in the event of an emergency, the e-mail contract acts to direct patients on how to appropriately use this form of communication, as well as its limitations. The incorporation of e-mail into the self-management of chronic diseases, such as IBD, has the potential to enhance patient care and safety.

ACKNOWLEDGEMENTS: Dr Ian Plener was the 2010 Ilona Diener Clinical Summer Student in Inflammatory Bowel Disease. Dr Andrew Hayward was the 2005 Ilona Diener Clinical Summer Student in Inflammatory Bowel Disease.

\section{REFERENCES}

1. Statistic Canada. Individual Internet Use and E-commerce. <www.statcan.gc.ca/daily-quotidien/111012/dq111012a-eng.htm> (Accessed July 10, 2012)

2. Brooks R, Menachemi N. Physicians' use of email with patients: Factors influencing electronic communication and adherence to best practices. J Med Internet Res 2006;8:e2.

3. Gaster B, Knight C, DeWitt D, Sheffield J, Assefi NP, Buchwald D. Physicians' use of and attitudes toward electronic mail for patient communication. J Gen Intern Med. 2003;18:385-9.

4. Minitwatts Marketing Group. Internet World Stats. $<$ www.internetworldstats.com/stats.htm> (Accessed June 30, 2012).

5. Halpert A, Dalton C, Palsson O, et al. Irritable bowel syndrome patient's ideal expectations and recent experiences with healthcare providers: A national survery. Dig Dis Sci 2010; 55:375-83.

6. Gullo K. Many nationwide believe in the potential benefits of electronic medical records and are interested in online communication with physicians. The Wall Street Journal Online Health Care Poll Newsletter, March 2005.

7. Kleiner K, Akers R, Burke B, Werner E. Parent and physician attitudes regarding electronic communication in pediatric practices. Pediatr 2002;109:740-4.

8. Moyer C, Stern D, Katz S, Fendrick AM. "We got mail": Electronic communication between physicians and patients. Am J Manag C 1999;5:1513-22.

9. Couchman G, Forjuoh S, Rascoe T. E-mail communications in family practice: What do patients expect? J Fam Pract 2001;50:414-8.

10. Lacher D, Nelson E, Bylsma W, Spena R. Computer use and needs of internists: A survey of members of the American College of Physicians-American Society of Internal Medicine. Proc AMIA Symp 2000:453-56. 
11. Castren J, Niemi M, Virjo I. Use of email for patient communication in student health care: A cross-sectional study. Med Inf. 2005;5:2.

12. Liederman E, Morefield CS. Web messaging: A new tool for patient-physician communication. JAMA 2003;10:260-70.

13. Kassirer J. Patients, physicians, and the Internet. Health Aff 2000;19:115-23

14. Katz S, Moyer C, Cox D, Stern D. Effect of a triage-based e-mail system on clinic resource use and patient and physician satisfaction in primary care: A randomized controlled trial. J Gen Intern Med 2003;18:736-44.

15. White C, Moyer C, Stern D, Katz S. A content analysis of e-mail communication between patients and their providers: Patients get the message. JAMA 2004;11:260-7.

16. Car J, Sheikh A. Email consultations in health care: 1 - scope and effectiveness. Br Med J 2004;329:435-8.

17. Dunbar P, Madigan D, Grohskopf L, et al. A two-way messaging system to enhance antiretroviral adherence. JAMA 2003;10:11-5.

18. Patt M, Houston T, Jenckes M, Sands D, Ford DE. Doctors who are using e-mail with their patients: A qualitative exploration. J Med Internet Res 2003;5:e9.

19. Deakin T, McShane C, Cade J, Williams R. Group based training for self-management strategies in people with type 2 diabetes mellitus. Cochrane Database Syst Rev 2005.

20. Bourbeau J, Julien M, Maltais F, et al. Reduction of hospital utilization in patients with chronic obstructive pulmonary disease: A disease-specific self-management intervention. Arch Intern Med 2003;163:585-91

21. Saibil F, Lai E, Hayward A, Yip J, Gilbert C. Self-management for people with inflammatory bowel disease. Can J Gastroenterol 2008;22:281-7.

22. Cross R, Finkelstein J. Feasibility and acceptance of a home telemanagement system in patients with inflammatory bowel disease: A 6-month pilot study. Dig Dis Sci 2007;52:357-64.

23. Kennedy AP, Nelson E, Reeves D, et al. A randomised controlled trial to assess the effectiveness and cost of a patient orientated self-management approach to chronic inflammatory bowel disease. Gut 2004;53:1639-45.

24. AAFP. Making a case for online physician-patient communication. It can improve communications, practice efficiency and maybe even the bottom line. Fam Pract Manag 2008;15:A3-A6.

25. Canadian Medical Protective Association (CMPA). Use of email with your patients, legal risk. <www.cmpa-acpm.ca/cmpapd04/docs/ resource_files/infosheets/2005/com_is0586-e.cfm> (Accessed July 5, 2012)

26. Car J, Sheikh A. Email consultations in health care: 2. Acceptability and safe application. BMJ 2004;329:439-42.

27. Medem Inc. eRisk Working Group for Healthcare's Guidelines for Online Communication. < www.medem.com/phy/phy_ eriskguidelines.cfm 2007> (Accessed July 12, 2012)

28. Potts H, Wyatt J. Survey of doctors' experience of patients using the Internet. J Med Internet Res 2002;4:e5.

29. Ontario Government and Ontario Medical Association. McGuinty Government and OMA Protecting Gains in Health Care. $<$ http://news.ontario.ca/mohltc/en/2012/11/ontario-and-oma-reachagreement.html $>$ (Accessed July 15, 2012).

30. Leong S, Gingrich D, Lewis P, Mauger D, George J. Enhancing doctor-patient communication using email: A pilot study. J Am Board Fam Pract 2005;18:180-8.

31. Virji A, Yarnall K, Krause K, et al. Use of email in a family practice setting: opportunities and challenges in patient- and physicianinitiated communication. BMC Med 2006;4:18

32. Pondichetty V, Penn D. The progressive roles of electronic medicine: Benefits, concerns, and costs. Am J Med Sci 2004;328:94-9.

33. Ceresia P, Crolla D. Physician-patient email communication: Legal risks. The Canadian Medical Protective Association Information Sheet. December 2005.

34. Katz S, Moyer, C. The emerging role of online communication between patients and their providers. J Gen Intern Med 2004;19:978-83. 


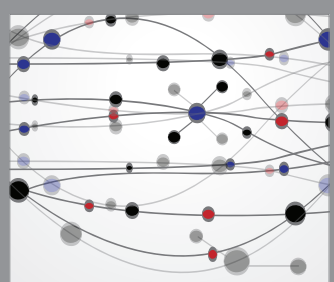

The Scientific World Journal
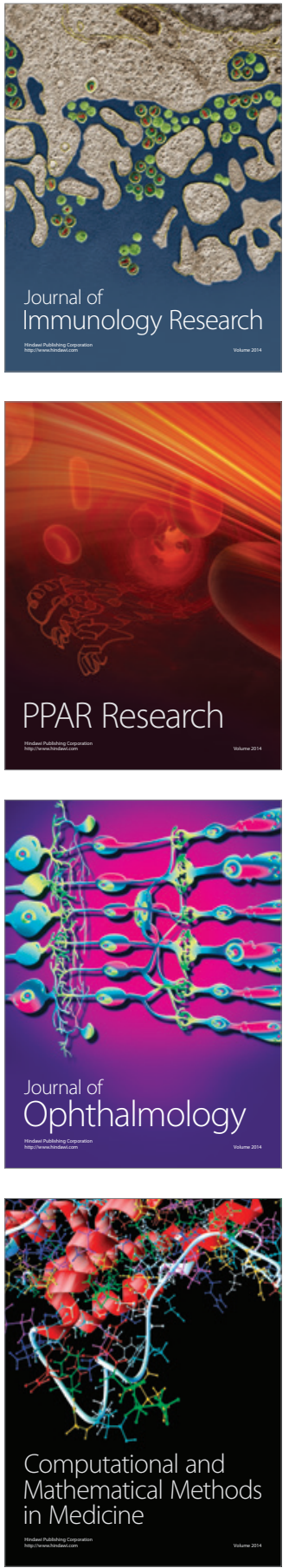

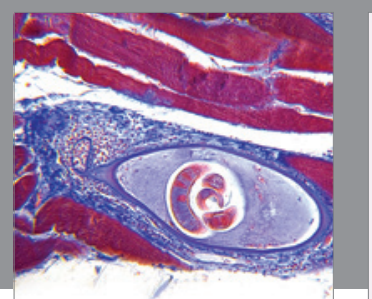

Gastroenterology Research and Practice

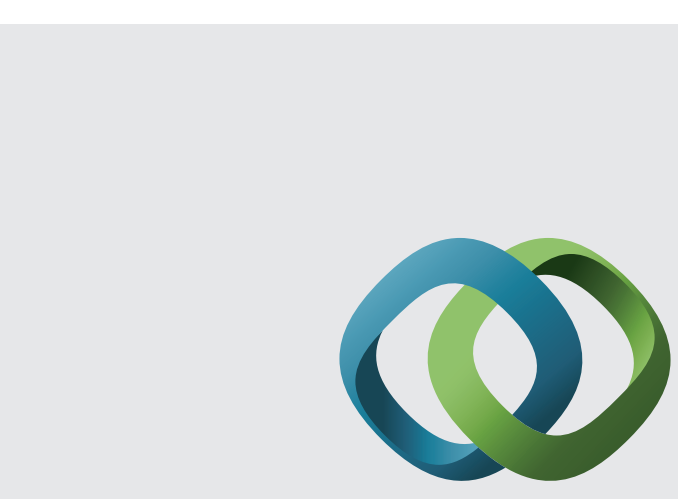

\section{Hindawi}

Submit your manuscripts at

http://www.hindawi.com
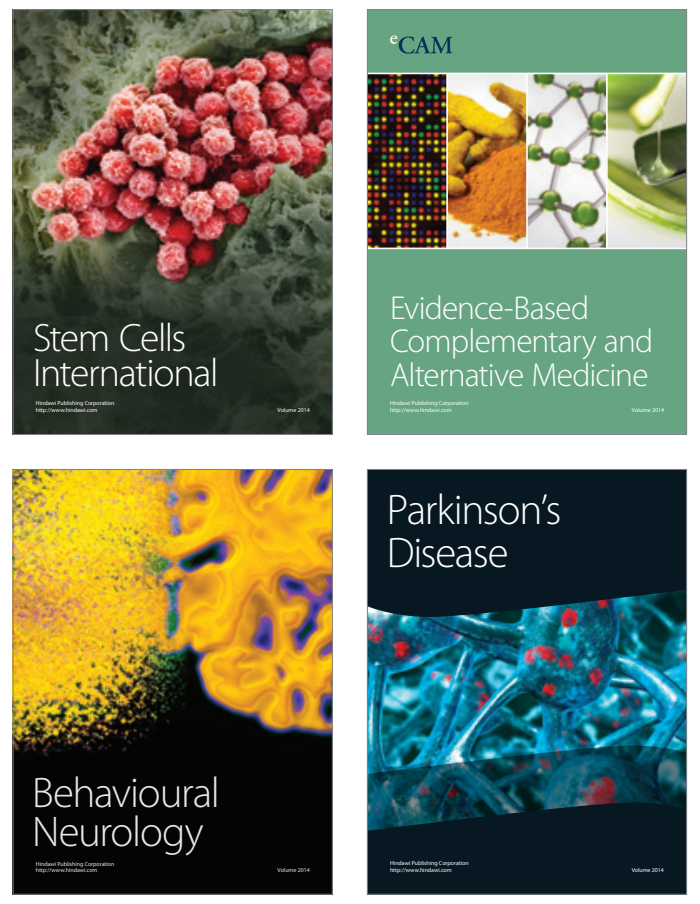
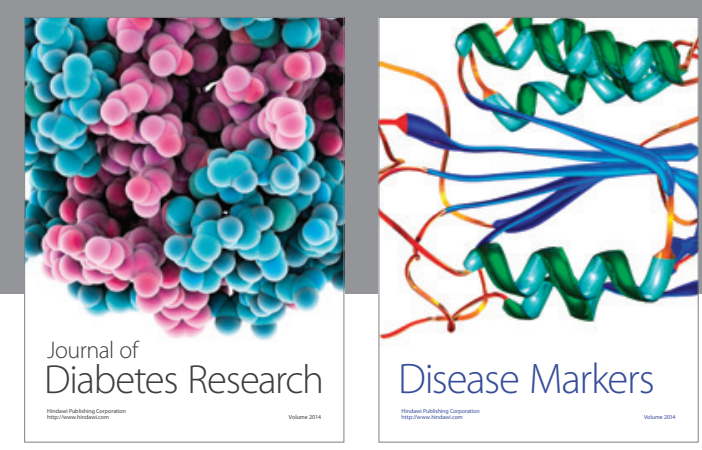

Disease Markers
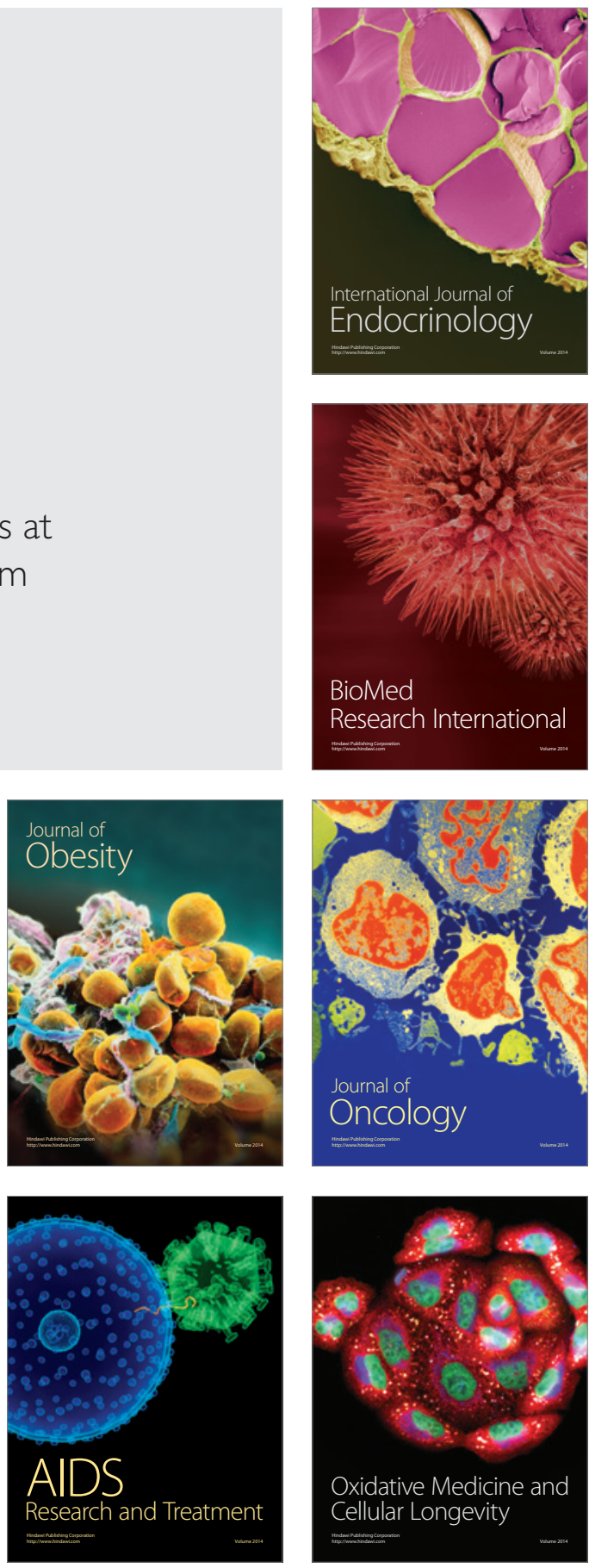